\title{
TRABALHO E EDUCAÇÃO SOB O CORONA VÍRUS NO BRASIL $^{*}$
}

Fabiane Santana Previtali

Cílson César Fagiani

Conseguir realizar o despotismo graças ao sufrágio universal! O miserável deu um golpe de Estado autoritário recorrendo à obediência bovina do povo! Está nos mostrando como será a democracia amanhã.

Umberto Eco, O Cemitério de Praga.

\section{Introdução}

Covid-19 é o nome científico da nova doença viral, causada pelo Coronavirus, cujo nome se deve ao seu aspecto de coroa. A doença assemelha-se à gripe e seus sintomas como tosse e febre pode afetar drasticamente o sistema respiratório, principalmente o pulmão, dificultando a respiração, sobrecarregando os músculos envolvidos nesta e levando ao óbito caso a pessoa não seja rapidamente colocada sob um respirador mecânico, em uma UTI hospitalar.

A forma de contágio é "simples" como qualquer outro vírus gripal e se espalha de forma exponencial. A principal forma de contágio da doença é o contato com uma pessoa infectada, que transmite o vírus por meio de tosse e espirros. Ele também se propaga quando a pessoa toca em uma superfície ou objeto contaminado. Uma vez que ainda não há tratamento medicamentoso ou vacina disponíveis, a Organização Mundial da Saúde (OMS) decretou estado de pandemia, isto é, situação em que uma doença infecciosa afeta um grande número de pessoas espalhadas pelo mundo e recomenda que os governos das na-

${ }^{*}$ DOI - 10.29388/978-65-86678-07-9-0-f.123-136 
ções adotem medidas de contenção, dentre elas, a mais importante, a do isolamento social.

No mundo, os governantes mais compromissados com as vidas humanas sob sua responsabilidade têm levado a sério essas recomendações. Boris Johnson, primeiro-ministro do Reino Unido, pertencente ao Partido Conservador, que considerava desnecessárias as medidas de isolamento, após ser acometido pela doença e ter sido tratado pelo sistema de saúde público, o "National Health System" (NHS), reconsiderou sua fala anterior e ainda, começou a rever sua política de sucateamento do NHS. A Suécia também não fez nada e paga o preço do aumento das mortes da população. O mesmo caminho é seguido por Donald Trump nos Estados Unidos.

O Brasil, onde o primeiro caso registado foi em 25 de fevereiro de 2020, é agora, o país que tem o maior número de casos e mortes por Covid-19 na América Latina (105 222 infecções e 7288 casos, respectivamente, registrados no dia 5 de maio, números muito provavelmente subestimados (CARTA MAIOR, 08/05/2020) e está em sexto lugar em casos no mundo. Os maiores focos são as cidades grandes como São Paulo e Rio de Janeiro, mas já há sinais de que a infecção está se deslocando para o interior dos estados, onde estão localizadas cidades menores.

O grande problema é que as pessoas precisam ser hospitalizadas e o Sistema Único de Saúde (SUS) brasileiro não dispõe de provisões adequadas de leitos com cuidados intensivos e ventiladores, em grande medida, porque vem sofrendo cada vez mais um recrudescimento com medidas neoliberais, com redução de investimentos técnicos e também de pessoal especializado de carreira além do sucateamento de sua estrutura. A gestão just-in-time na esfera pública impõe ao serviço de saúde uma rede de trabalhadores/as terceirizados/as, sob contratos temporários e em condições precárias, sendo expostos/as à contaminação por falta de equipamentos adequados, ao mesmo tempo em que planos de saúde privados aumentam seus lucros. 
Ante esse quadro, o presidente Jair Bolsonaro, nosso "Crapulinski” (ANTUNES, 2020), desconsidera a importância das medidas de isolamento, chegando a chamar a doença de "gripezinha" e afirmando, em pronunciamento nacional, que as pessoas saíssem do isolamento e fossem trabalhar. Em mais de uma vez ele passeou pelas ruas de Brasília, causando aglomerações, cumprimentando a população e expondoas ao perigo do contágio. Quando questionado por jornalistas sobre o número crescente de mortes, ele respondeu: "E daí? Lamento, quer que eu faça o quê?"

É sabido que a doença não escolhe quem atacar, sendo nesse aspecto muito democrática. Por isso é comum a expressão: "estamos todos no mesmo barco". Bem, mas é preciso considerar que os barcos são bem diferentes, indo desde canoinhas até transatlânticos. Isso significa dizer que algumas pessoas são muito mais vulneráveis a pegar o vírus que outras, não porque o vírus as escolheu, mas porque, deliberadamente, foram deixadas em suas barquinhas à deriva, ao lado dos transatlânticos que, no movimento das ondas do mar, as afunda. Nos vem à mente o filme "Titanic" ${ }^{2}$, que conta a história do naufrágio de um grande navio saindo da Inglaterra para os Estados Unidos quando muitos passageiros, de três diferentes classes ${ }^{3}$ a bordo, morreram. Mas, os que estavam na terceira classe, composta majoritariamente por tra-

\footnotetext{
${ }^{1}$ Carta Maior. Revista Lancet: Brasil precisa dar uma resposta clara ao "E daí?" de seu presidente. 08/05/2020. Disponível em: <https://www.cartamaior.com.br/?/Editoria/ Politica/Revista-Lancet-Brasil-precisa-dar-uma-resposta-clara-ao-E-dai-de-seu-presidente/4/47436>. Acesso em: 08 de maio. de 2020.

${ }^{2}$ Filme estadunidense produzido em 1997, que conta a história do naufrágio do tran satlântico Titanic em 1912. A direção foi de James Cameron, tendo com atores principais Kate Winslet e Leonardo DiCaprio. $194 \mathrm{mim}$.

${ }^{3}$ Os passageiros do Titanic estavam divididos em três classes separadas, determinado não só pelo preço de seu bilhete, mas pela riqueza e classe social: os que viajavam em primeira classe, a maioria deles os passageiros mais ricos a bordo, incluíam membros proeminentes da classe alta, empresários, políticos, militares de alto escalão, indus triais, banqueiros, artistas, socialites e atletas profissionais. Os passageiros da segunda classe eram viajantes da classe média e incluíam professores, autores, clérigos e turistas. Os passageiros da terceira classe eram principalmente imigrantes. Disponível em: <https://pt.wikipedia.org/wiki/Passageiros do RMS Titanic\#Terceira classe>. Acesso em: 08 de maio. de 2020.
} 
balhadores/as imigrantes morreram mais porque seus compartimentos ficavam trancados para que não se misturassem com as classes mais abastadas. Foram impedidos de subir para o convés.

Sob a pandemia, os números e as imagens mostram que as pessoas pertencentes à classe trabalhadora, em seus extratos mais precarizados estão morrendo mais. Não porque têm menos sorte ou porque "Deus quer", mas porque homens poderosos e endinheirados assim o desejam. Como já disse Engels (2008), as epidemias servem para destruir o excesso de trabalho.

Mundialmente, aproximadamente 2,7 bilhões de trabalhadores/ as, representando cerca de $81 \%$ da força de trabalho do mundo estão sendo atingidos pela pandemia (ILO, 2020), sendo os mais afetados os/ as trabalhadores/as informais, com empregos mal remunerados, de baixa qualificação e baixa proteção social. A informalidade atinge 20,9\% da classe trabalhadora na Europa e Ásia Central e 36,1\% nas Américas (ILO, 2020). Com relação ao trabalho em tempo integral, o órgão estima uma redução de $6,7 \%$ das horas de trabalho no segundo trimestre de 2020 no mercado de trabalho global, o equivalente a 195 milhões de trabalhadores/as.

No Brasil, segundo Sayuri (2020), cerca de $72 \%$ da classe trabalhadora teme perder renda por causa dos impactos econômicos da pandemia, num contexto de 11,9 milhões de desempregados e 38,4 milhões de trabalhadores/as informais. A autora observa ainda que as mulheres são a maioria nos trabalhos informais, como manicures, cuidadoras, vendedoras de produtos na rua, trabalhadoras domésticas sem direitos trabalhistas e diaristas. Esse novo cenário sócio-econômico-político lança luzes sobre as enormes discrepâncias sociais, a concentração da renda e o concomitante aumento da pobreza da classe trabalhadora e o escarnio com que essas questões são tratadas no âmbito do neoliberalismo.

O relatório da ILO/Monitor de 29 de abril de 2020, apresenta uma classificação dos setores econômicos mais vulneráveis ao impacto da pandemia, quais sejam: o comércio por atacado e varejo, conserto 
de veículos e motocicletas, manufatura, hospedagem e serviços de alimentação, imóveis, atividades comerciais e administrativas, totalizando aproximadamente 47 milhões de empregadores, representando cerca de $54 \%$ de todos os empregadores no mundo.

No Brasil, esses setores correspondem a uma parcela significativa das micro, pequenas e médias empresas ${ }^{4}$, muitas delas na informalidade, totalizando 47\% em 2019 (SEBRAE, 2020). Destaca-se que as micro e pequenas empresas (MPEs) responderam por $30 \%$ da economia do país e foram responsáveis pela criação de cerca de 13,5 milhões de empregos em 2019 (SEBRAE, 2020). É aqui que estão os trabalhadores/as que se transmutam em empreendedores, como os motoristas e entregadores, utilizando carros, motos e bicicletas e prestadores de serviços em geral, como as empregadas domésticas, as manicures, as massagistas, todos/as vinculados/as a plataformas digitais (apps), sem vínculos empregatícios ou assistência social. São empregadores/as de si mesmos, expostos às vicissitudes de mercado e deixados à deriva, em seus barquinhos, na tempestade causada pelo Covid-19. São esses trabalhadores/as que estão nas filas da Caixa Econômica Federal (CEF), tentando obter, por direito, o auxílio emergencial de $\mathrm{R} \$ 600,00$, mas que não conseguem por "erro de cadastro" ou "inconsistência de dados" conforme mensagem recebida do banco, via app, em seus celulares.

Segundo o Cadastro Geral de Empregados e Desempregados (CAGED, 2019), das 644.079 vagas de trabalho formal criadas em $2019,21,63 \%$ a mais que em 2018, 16,5\% (106 mil) foram nas modalidades de trabalho intermitente ou de regime de tempo parcial, sendo que das 106 mil vagas, 85.716 vagas foram relativas ao trabalho intermitente (CAGED, 2020). Ainda, e acordo com o CAGED (2019), o se-

\footnotetext{
${ }^{4}$ Seguimos a classificação das empresas por critério de pessoas ocupadas por setor econômico, sendo as microempresas com até 9 pessoas ocupadas (serviços) e 19 pes soas ocupadas (indústria); pequenas empresas de 10 a 49 pessoas ocupadas (serviços) e 20 a 49 pessoas ocupadas (indústria); médias empresas de 50 a 99 pessoas ocupadas (serviços) e 100 a 999 (indústria); grandes empresas, a partir de 100 pessoas ocupa das (serviços) e a partir de 500 pessoas ocupadas (indústria). Consultar SEBRAE (2020).
} 
tor que mais gerou empregos em 2019 foi o de serviços, que teve 6.966.824 admissões e 6.584.299 desligamentos, implicando saldo de 382.525 postos de trabalho e crescimento de $2,22 \%$ sobre o ano anterior. Em contrapartida, o setor que menos apresentou crescimento do emprego foi a administração pública, totalizando 822 empregos e aumento de $0,10 \%$ em relação ao ano anterior. Chama à atenção o recrudescimento do setor público, resultado, em grande medida, da redução drástica dos investimentos por parte dos governos estaduais e federal, especialmente em setores como a saúde e a educação.

A área da educação está entre os setores menos atingidos economicamente pela pandemia no mundo (ILO/MONITOR, 2020), dado que se encontra, especialmente a educação básica, vinculada à administração pública e os estudantes ainda não se encontram em idade ativa para o trabalho ou não trabalham. No entanto, o impacto es tritamente econômico é apenas a ponta de um iceberg, considerandose a estrutura social e as relações sociais que a consubstanciam. Segundo Jouli e Zambroni (2020), há mais de 1.500 milhões de estudantes atingidos pelo fechamento das escolas em 191 países, correspondendo a $90 \%$ da população estudantil mundial. Os autores atentam ainda que aproximadamente 826 milhões de estudantes no mundo não possuem acesso a um computador em suas casas e cerca de 706 milhões não têm internet em suas casas. Mesmo diante desse quadro, para solucionar a questão, os governos mundiais estão buscando desenvolver plataformas de ensino virtuais.

O impacto aqui, portanto, é de outra natureza e está relacionado ao avanço das tecnologias digitais na educação no contexto da pandemia, de forma aligeirada, sem um debate mais aprofundado acerca de seu alcance e de sua eficácia no ensino e aprendizagem e, majoritariamente, com interesses econômicos, pois estamos falando de empresas educacionais privadas a vender plataformas e conteúdos. Como afirmam Jouli e Zambroni (2020, p. 7), "la pandemia Covid-19 nos muestra que el mundo ya no considera imprescindible la presencia 
física de los docentes em un aula para que los niños, niñas, jóvenes y adultos se formen o eduquen" 5 .

No Brasil o sistema educacional, segundo Lehr (2020) congrega aproximadamente 60 milhões de estudantes da educação básica, profissional e superior, envolvendo ainda cerca de 2.4 milhões de professores/as, sem contar um importante contingente de profissionais afins. No país, a forma virtual encontrada para a contenção da pandemia, concomitantemente à manutenção do funcionamento das instituições educacionais, públicas ou privadas, traz consigo uma perversidade explícita que aprofunda as desigualdades sociais e educacionais já existentes na sociedade, deixando os mais pobres totalmente excluídos e desamparados.

No ensino superior, o MEC, através do Comitê Operativo de Emergência, teve como uma de suas primeiras decisões, em 18 de março de 2020, a flexibilização das aulas presenciais em forma de EAD, medida válida por 30 dias e prorrogável de acordo com orientações do Ministério da Saúde, neste caso foi prorrogado por mais 30 a partir de 15 de maio de 2020. A medida contempla o sistema federal de ensino, composto pelas universidades federais, pelos institutos federais, pelo Colégio Pedro II, pelo Instituto Nacional de Educação de Surdos (INES), Instituto Benjamin Constant (IBC), e pelas universidades e faculdades privadas, com a necessidade de informar a opção ao MEC em até 15 dias. No sistema federal de ensino há uma grande resistência a esta implementação na graduação e na pós-graduação, já nas instituições particulares é algo que vem sendo recorrente.

Quanto à educação básica, esta tem seu funcionamento definido pelas prefeituras e pelos estados e em todo o Brasil foram suspensas as aulas presenciais, tanto na rede pública quanto na privada, sendo substituídas por atividades virtuais, ou seja, EAD. Neste interim o governo federal publicou em 1 de abril de 2020, em edição extra do Diário Oficial da União, medida provisória que promove ajustes no calen-

\footnotetext{
${ }^{5}$ Tradução livre: A pandemia do Covid-19 nos mostra que o mundo já não considera imprescindível a presença física dos docentes em uma aula para que os meninos e meninas, jovens e adultos se formem ou se eduquem.
} 
dário escolar de 2020 (MP 934/2020). A medida vale para a educação básica e para a superior. A medida dispensa, em caráter excepcional, as escolas de educação básica da obrigatoriedade de observar o mínimo de 200 dias letivos de efetivo trabalho escolar e determina que a carga horária mínima de oitocentas horas deve ser cumprida, nos termos das normas a serem editadas pelos respectivos sistemas de ensino.

No estado de Minas Gerais, localizado na região Sudeste do pais $^{6}$, a Secretaria Estadual de Educação (SEE) elaborou um Regime de Estudo não Presencial, ou seja, uma EAD, composto por um Plano de Estudo Tutorado (PET) e programa de TV em parceria com a Rede Minas, com apostilas mensais de orientação de estudo e atividades por ano de escolaridade ( $1^{\circ}$ ao $9^{\circ}$ ano do ensino fundamental e $1^{\circ}$ ao $3^{\circ}$ ano do ensino médio). A distribuição das apostilas feita prioritariamente por meios virtuais (site da SEE, e-mail e WhatsApp dos pais cadastrados nas escolas, entre outros) com início marcado para o dia 4 de maio de 2020 (AGÊNCIA MINAS GERAIS, 16/04/2020).

O programa de TV, “Se Liga na Educação", é transmitido de segunda a sexta-feira, sempre das 7 h30 às 12 h30 pela Rede Minas. Nele, são apresentados conteúdos em que, geralmente, os estudantes têm mais dificuldades, além de debates específicos sobre o Exame Nacional do Ensino Médio (Enem). São quatro horas de aulas gravadas (das $7 \mathrm{~h} 30$ às 11h30), e uma hora (11h30 às 12h30) ao vivo, período no qual os/as estudantes poderm interagir com os professores/as no estúdio, por meio das redes sociais, WhatsApp e telefone (AGÊNCIA MINAS GERAIS, 16/04/2020).

Só para lembrar, as crianças no primeiro ciclo do ensino fundamental tem entre 6 e 10 anos de idade, esse talvez o nível mais crítico, pois são totalmente dependentes das orientações de um adulto, as quais devem ser qualificadas, voltadas para o ensino e aprendizagem de conteúdos específicos em momentos específicos, com metodologias adequadas, que não devem ser padronizadas, considerando-se as pecu-

\footnotetext{
${ }^{6}$ A região sudeste é composta ainda pelos estados de São Paulo, Rio de Janeiro e Espírito Santo.
} 
liaridades de cada criança. Esse conjunto de atividades deve ser desenvolvido pelo/a profissional docente, formado/a para isso, e que é suprimido no caso do EAD. Assim, em todos os níveis de ensino, confundese a formação escolar com a quantidade de informação adquirida, deixando-se de lado aspectos importantíssimos para a real formação, isto é, humana, crítica e consciente, dos sujeitos sociais.

Cumpre ressaltar que contexto socioeconômico e estrutural das famílias já proporcionava, muito antes da pandemia, dificuldades no acompanhamento do processo de ensino e aprendizagem das crianças e adolescentes pelas famílias, incluindo a segunda fase do ensino fundamental e ensino médio. Agora temos o agravo da situação, principalmente para a grande maioria das famílias que não tem preparo psicopedagógico e condição econômica para acompanhar a vida escolar de seus filhos/as, não que sejam culpados por isso, mas como consequência de uma estrutura histórica, econômica e social de abandono, exclusão e discriminação. E, para piorar, temos um (des)governo, tanto a nível federal como estadual, no caso Minas Gerais, que tem seus objetivos muito bem claros quanto ao valor que "não" dá para a educação pública, incluindo-se nesta os jovens trabalhadores/as em formação e também os profissionais da educação ${ }^{7}$. A estes, o governador do estado informou, em março, que não tinha previsão de pagamento dos seus salários, em plena pandemia.

Dados do IBGE (2020), através da pesquisa nacional por amostra de domicílios contínua de 2018 aponta que 53,7\% e 55,9\% dos domicílios particulares não tem computadores no estado de Minas Gerais e no Brasil, respectivamente. Ainda: não utilizam internet $20,7 \%$ e $20,9 \%$, não utilizam internet pelo microcomputador ou tablet $48,2 \%$ e $49,5 \%$, não utilizam a internet por telefone móvel celular $0,8 \%$ e $0,8 \%$ e não possuem televisão $3,0 \%$ e 3,6\% respectivamente no estado de $\mathrm{Mi}$ -

\footnotetext{
${ }^{7}$ Vale dizer ainda que os docentes da educação básica estadual se encontravam em greve desde o início do ano letivo pelo pagamento do Piso Nacional da Educação, pagamento do $13^{\circ}$ salário de 2019 e isonomia salarial com outras categorias profissi onais quando teve início a pandemia. Consultar Sindicato Único dos Trabalhadores em Educação de Minas Gerais (SIND-UTE). Disponível em: http://sindutemg.org.br/estamos-juntos-na-luta/. Acesso em 12 de març. 2020.
} 
nas Gerais e no Brasil (Tabela 1). Vale lembrar que os professores/professoras da educação básica estão incluídos nesse quadro. Como sempre, ou seja, desde antes da pandemia "resta" a televisão para "educar" o povo, pois o principal meio de acesso à internet, o telefone móvel celular, é utilizado, pela sua praticidade, nos aplicativos de carros e taxis (para o trabalho uberizado), de filmes e séries (para o entretenimento) e pedido de comida. Ademais, essa ferramenta é no mínimo, muito inapropriada para leitura de textos didáticos e realização de tarefas escolares.

Tabela 1- Características dos domicílios do estado de Minas Gerais e do Brasil quanto a posse de equipamentos e meios de acesso à Internet.

\begin{tabular}{|c|c|c|}
\hline $\begin{array}{c}\text { Características dos } \\
\text { domicílios particulares }\end{array}$ & Estado de Minas Gerais & Brasil \\
\hline $\begin{array}{c}\text { Possui microcomputador } \\
\text { ou tablet }\end{array}$ & 46,3 & 44,1 \\
\hline Utilizam Internet & 79,3 & 79,1 \\
\hline $\begin{array}{c}\text { Utilizam Internet somen- } \\
\text { te por microcomputador } \\
\text { ou tablet }\end{array}$ & 51,8 & 50,5 \\
\hline $\begin{array}{c}\text { Utilizam Internet somen- } \\
\text { te por telefone móvel ce- } \\
\text { lular }\end{array}$ & 99,2 & 99,2 \\
\hline Possui televisão & 97,0 & 96,4 \\
\hline
\end{tabular}

Fonte: IBGE (2020)

Convém destacar que16 estados do país planejam considerar as atividades virtuais como oficiais para contagem da carga horária letiva equivalente às aulas presenciais, incluindo o estado de Minas Gerais (G1/EDUCAÇÃO, 17/05/2020). Nesse contexto, o Sindicato Único dos Trabalhadores em Educação de Minas Gerais (SIND-UTE) declarou que as escolas públicas estaduais não tiveram investimentos adequados para o uso dessa ferramenta de ensino que requer planejamen- 
to, acompanhamento e avaliação processual das atividades e enfatizou a necessidade do poder público garantir a educação escolar com padrão de qualidade universal, conforme a Constituição Federal e a Lei de Diretrizes e Base (LDB), sendo o lema "Nenhuma Criança Fora da Escola" válido para qualquer situação de oferta escolar (presencial ou remota).

Quanto aos/as docentes, estes são constrangidos/as e se "reiventar" para as aulas virtuais, a partir de seus próprios esforços e equipamentos enquanto os empregadores de empresas educacionais, especialmente no ensino superior, amparados, pela MP 936, promovem suspensão de contratos e cortes salariais. No caso da educação básica pública, prefeitos e governadores, também se valendo das novas regras laborais sob a pandemia, estão reduzindo salários de servidores em até $70 \%$ e encerrando contratos de trabalho de terceirizados. Um exemplo é o caso de aproximadamente 150 profissionais da educação básica, incluindo-se docentes, monitores e secretários, na cidade de Lagoa Formosa, Minas Gerais, que tiveram seus contratos de trabalho rescindidos no mês de abril pela Secretaria Municipal de Educação, numa comunicação por WhatsApp, em virtude da suspensão das aulas (MOTA, 2020).

Nesse contexto de pandemia, tudo é motivo para precarizar ainda mais a educação, lembrando que quando foi votada a Emenda Constitucional N. ${ }^{\circ}$, que limita os gastos do governo por durante 20 anos, não existia a pandemia. Ademais, os/as professores/as da rede pública têm tido seus rendimentos fragmentados e diminuídos desde muito antes da pandemia.

\section{Considerações Finais}

A pandemia atual foi considerada pela ONU como a pior crise de saúde pública mundial desde a II Guerra Mundial e coloca em questão a difusão desenfreada do neoliberalismo e da globalização com exploração dos recursos naturais e trabalho humano a custos bai- 
xos para a produção de mercadorias lucrativas. Nesse contexto, pesquisas importantes na área da saúde humana deixam de ser realizadas porque demandam investimentos custosos e em longo prazo. O Estado neoliberal não se desresponsabiliza em realizá-las e as transfere para laboratórios privados que, por sua vez, preferem investir em pesquisas de maior e mais rápido retorno financeiro, como skincare.

Podemos perceber agora o quanto é importante do ponto de vista da vida humana a presença de um Estado socialmente referenciado e que regule a ordem econômica quanto aquilo que é de interesse público e o é de interesse privado, não deixando este último avançar sobre as necessidades fundamentais da vida humana em seu metabolismo com o meio natural, pois dessa maneira continuaremos a ver que quem tem dinheiro tem saúde, habitação, educação, lazer e quem não tem dinheiro, morre. E continuaremos escutando: "E daí? “. E serão muitos mais "E daís" ainda. A questão que se coloca é: Até quando? O que mais será necessário para, em vez de "E dai? “, tenhamos ações políticas que salvem as vidas em toda sua condição humana?

\section{Referencias}

ANTUNES, R. O delírio de Crapulinski. Blog da Boitempo. Disponível em: $<$ https://blogdaboitempo.com.br/2020/04/24/ricardo-antunes-odelirio-de-crapulinski/.> Acesso em: 24 abr. 2020.

AGÊNCIA MINAS GERAIS. Educação. Rede estadual de ensino terá regime de estudo não presencial. 16 de abril de 2020. Disponível em: $<$ http://www.agenciaminas.mg.gov.br/noticia/rede-estadual-deensino-tera-regime-de-estudo-nao-presencial.> Acesso em: 16 de abr. 2020.

CADASTRO GERAL DE EMPREGADOS E DESEMPREGADOS (CAGED). Sumário Executivo. Janeiro-Dezembro de 2019. 2019. Disponível em: $<$ http://trabalho.gov.br/images/Noticias/Jan-2020/ Caged Dezembro.pdf $>$. Acesso em: 10 de fev. de 2020. 
CARTA MAIOR. Revista Lancet. Brasil precisa dar uma resposta clara ao "E daí?" de seu presidente. 08 de maio de 2020. Disponível em: $<$ https://www.cartamaior.com.br/?/Editoria/Politica/Revista-LancetBrasil-precisa-dar-uma-resposta-clara-ao-E-dai-de-seu-presidente/ 4/47436 >. Acesso em: 09 maio. 2020.

ENGELS, F. A Situação da Classe Trabalhadora na Inglaterra. São Paulo: Boitempo. 2008.

G1. EDUCAÇÃO. Estudantes, pais e professores narram 'apagão' do ensino público na pandemia; em 7 estados e no DF, atividade remota não vai contar para o ano letivo. 21 de maio de 2020. Disponível em: $<$ https://g1.globo.com/educacao/noticia/2020/05/21/estudantes-paise-professores-narram-apagao-do-ensino-publico-na-pandemia-em-7estados-e-no-df-atividade-remota-nao-vai-contar-para-o-ano-letivo.ghtml >. Acesso em: 21 maio. 2020.

INTERNATIONAL LABOUR ORGANIZATION (ILO). ILO Monitor 2nd edition: COVID-19 and the world of work Updated estimates and analysis. Disponível em: <https://www.ilo.org/wcmsp5/groups/public/---dgreports/---dcomm/documents/briefingnote/ wcms_740877.pdf>. Acesso em: 10 abr. 2020.

INTERNATIONAL LABOUR ORGANIZATION (ILO). World Employment and Social Outlook: Trends 2019. Geneva, 2019. Disponível em: <https://www.ilo.org/global/research/global-reports/weso/2019/ WCMS 670542/lang--en/index.htm>. Acesso em 18 de mar. de 2020.

INSTITUTO DE GEOGRAFIA E ESTATÍSTICA - IBGE. Cidades. Acesso à internet e à televisão e posse de telefone móvel celular para uso pessoal. Disponível em: <https://cidades.ibge.gov.br/brasil/mg/ pesquisa/10070/64506?ano=2018\&localidade $1=0>$. Acesso em: $10 \mathrm{de}$ maio. 2020.

JOULI, L.; ZAMBRONI, P. La digitalización de la vida y sus impactos en el sistema educativo. Carta Maior. Educação. 3 de maio de 2020. 
Disponível em: <https://www.cartamaior.com.br $>$. Acesso em: 4 maio 2020.

LEHR, R. Em virtude da pandemia é necessário discutir o planejamento do sistema educacional. Carta Maior/Educação. 04/05/2020. Disponível em: < $\underline{\text { https://www.cartamaior.com.br/?/Editoria/Educacao/Em- }}$ virtude-da-pandemia-e-necessario-discutir-o-planejamento-do-sistema-educacional/54/47389> . Acesso em: 06 de maio. 2020.

MOTA, P. Professores da rede municipal de Lagoa Formosa têm contrato rescindido por causa do coronavirus. PatosJá. 16/04/2020. Disponível em: <https://patosja.com.br/busca/educacao $>$. Acesso em: 18 abr. 2020.

SAYURI, J. Nada disso é normal: como a Covid-19 escancara velhas anomalias do Brasil. TAB.OUL. Disponível em: $<$ https://tab.uol.com.br/noticias/redacao/2020/04/05/nada-disso-e-normal-como-a-covid19-escancara-velhas-anomalias-do-brasil.htm>. Acesso em: 5 abr. 2020.

SERVIÇO BRASILEIRO DE APOIO ÀS MICRO E PEQUENAS EMPRESAS - SEBRAE. Atualização de estudo sobre participação de micro e pequenas empresas na economia nacional. Março de 2020. Dis-

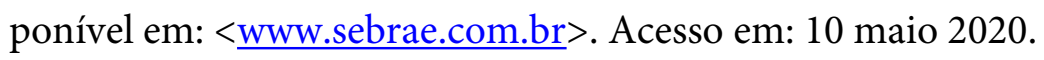

SINDICATO ÚNICO DOS TRABALHADORES EM EDUCAÇÃO DE MINAS GERAIS - SIND-UTE. Nota Pública da CNTE - O currículo escolar em tempos de pandemia do coronavírus. 27/03/2020. Disponível em: <http://sindutemg.org.br/noticias/nota-publica-da-cnteo-curriculo-escolar-em-tempos-de-pandemia-do-coronavirus/>. Acesso em: 28 mar. 2020. 